\title{
Multifunctional Cotton Fabrics Obtained by Modification with Silanes Containing Esters of Phosphoric Acid as Substituents
}

\author{
Marcin Przybylak ${ }^{1, *}$, Michał Dutkiewicz ${ }^{1,2}\left(\mathbb{D}\right.$, Karol Szubert $^{3}\left(\mathbb{D}\right.$, Hieronim Maciejewski ${ }^{1,3}(\mathbb{D}$ \\ and Szymon Rojewski ${ }^{4}$ (D) \\ 1 Poznan Science and Technology Park, Adam Mickiewicz University Foundation, Rubież 46, \\ 61-612 Poznań, Poland; midu@amu.edu.pl (M.D.); maciejm@amu.edu.pl (H.M.) \\ 2 Centre for Advanced Technologies, Adam Mickiewicz University, Uniwersytetu Poznańskiego 10, \\ 61-614 Poznań, Poland \\ 3 Faculty of Chemistry, Adam Mickiewicz University, Uniwersytetu Poznańskiego 8, 61-614 Poznań, Poland; \\ karolszu@amu.edu.pl \\ 4 Institute of Natural Fibres \& Medicinal Plants, Wojska Polskiego 71b, 60-630 Poznań, Poland; \\ szymon.rojewski@iwnirz.pl \\ * Correspondence: marcin.przybylak@ppnt.poznan.pl
}

Citation: Przybylak, M.; Dutkiewicz, M.; Szubert, K.; Maciejewski, H.; Rojewski, S. Multifunctional Cotton Fabrics Obtained by Modification with Silanes Containing Esters of Phosphoric Acid as Substituents. Materials 2021, 14, 1542. https:// doi.org/10.3390/ma14061542

Received: 11 February 2021

Accepted: 16 March 2021

Published: 21 March 2021

Publisher's Note: MDPI stays neutral with regard to jurisdictional claims in published maps and institutional affiliations.

Copyright: (c) 2021 by the authors. Licensee MDPI, Basel, Switzerland. This article is an open access article distributed under the terms and conditions of the Creative Commons Attribution (CC BY) license (https:// creativecommons.org/licenses/by/ $4.0 /)$.

\begin{abstract}
The development of novel flame retardants for cotton textiles that form a stable layer on textile fiber is of high economical and practical relevance. A novel flame retardant fluorinated phosphoric acid esters modified silicone resins for cotton modification were synthesized. The investigated phosphoric acid esters based compounds were substituted by a fluorinated chain or ring, and alkoxysilyl groups. The presence of alkoxysilyl groups allowed the formation of bonds with cellulose, while derivatives of phosphoric esters reduced the flammability of fabrics. Additionally, the presence of fluoride in their structures affected the hydrophobic properties. Cotton fabrics were modified in a simple one-step process by dip-coating method. The flame retardant properties of modified textiles were examined by performing microcalorimetric analysis, thermogravimetry analysis, and measuring oxygen index. The hydrophobicity was evaluated by measuring the water contact angle. The modified fabrics were characterized by SEM-EDS (Scanning Electron Microscopy with Energy Dispersive Spectroscopy) analysis and surface morphology. As a result of the tests, multifunctional fabrics were obtained.
\end{abstract}

Keywords: cotton; flame retardants; organosilicon; coating; multifunctional; water repellent

\section{Introduction}

Cotton fabrics are the most important branch of the natural textile industry. A strong ecological trend and growing awareness of consumers mean that the cotton fabric market is constantly growing. Cotton fabrics have many advantages such as soft touch, elasticity, and good mechanical properties. However, there is a problem in the flammability and hydrophilicity of cotton products. More and more stringent standards and safety requirements mean that it is necessary to look for new solutions to meet the expectations of producers and customers. To give fabrics new properties, such as being flame retardant or hydrophobic, they are subjected to modifications [1-3].

So far, natural textiles have usually been modified unidirectional to reach the flame retardancy or high hydrophobicity. A wide spectrum of flame retardant compounds has been used to protect fabric against fire. The most important group of compounds are halogen antipyrene; however, their use must be limited due to environmental protection [4-9]. There is, thankfully, a group of environmentally-safe fluorinated compounds. Such an example is the short-chain derivatives of fluorinated alcohols. Studies have shown that they do not pose a threat to humans and the environment and do not generate hazardous compounds during decomposition [10,11]. Phosphorus, as well as phosphorus and nitrogen-containing 
compounds which are effective in lowering flammability, has been also widely used [12-19]. Unfortunately, most of the investigated compounds are not able to bind permanently to the modified surface.

An interesting group of compounds used to reduce the flammability of natural fabrics is organosilicon compounds. The most popular form of organosilicon compounds is silica precursors, which are applied in the sol-gel process. These compounds can form multidimensional siloxane structures that insulate the fibers from the source of flames on the fabric surface [20-24]. Moreover, these siloxane networks can easily immobilize phosphorus or ammonium flame retardants [25-28].

Recent studies have focused on the synthesis of new organosilicon compounds having the ability to produce bonds with the cellulose and impart desired properties to surfaces subjected to the modification. There are literature reports on the synthesis of flame retardant compounds by substituting aminopropyltriethoxysilane with phosphorus and nitrogen derivatives. Derivatives such as 10-dihydro-9-oxa-10-phosphaphenanthrene-10oxide and isophorone diisocyanate [29] or dimethyl hydroxymethylphosphonate and cyanuric chloride were used [30]. In another work, aminopropyltriethoxysilane has been substituted with phosphoric acid and urea [31]. Silicon and phosphorus-containing flame retardant for cotton textiles have been also synthesized from dimethyl phosphonate and methylvinyldichlorsilane [32]. Polysiloxanes have been also used for the synthesis of flame retardant compounds with reactive groups, eg., 4-bromobutoxy-terminated poly(dimethylsiloxane) substituted with piperazine and phosphorus oxychloride [33]. Another paper presents the synthesis of poly(4-iodobutoxy)methylsiloxane with N-methyl3-(dimethoxydibenzyloxyphosphoryl)acrylamide to obtain a modifier for cotton fabric [34]. However, many of the developed methods have some disadvantages like a complicated impregnation process, low fire retardant effect, low washing resistance, or high add-on value necessary to obtain a satisfactory flame-retardant effect. The research group led by $\mathrm{Hu}$ S. et al. obtained a relatively low fire-retardant effect despite the use of high concentrations of the fire-retardant compound [29]. However, in the case of the research by Tian $P$ et al., it was necessary to use an add-on modifier at the level of $30 \%$ to obtain a good fireproof effect of the fabrics [31].

In our previous studies, we reduced the flammability of fabrics both by using immobilization of ammonium phosphates in a silica sol and by synthesizing new compounds capable of binding with cellulose [35]. We have developed the synthesis of alkoxysilyl groups containing cyclophosphazenes used to modify cotton fabrics, reducing their flammability [36]. Moreover, we researched the synthesis of silanes, polysiloxanes, and silsesquioxanes containing alkoxysilyl and fluoroalkyl groups, the use of which for the fabric modification resulted in the preparation of superhydrophobic, and resistant for multiple washing processes cotton [37,38]. Experience gained in the synthesis of functionalized organosilicon compounds prompted us to the synthesis of new silanes containing three different functional groups. The research was aimed at obtaining compounds capable of producing covalent bonds with cellulose hydroxyl groups, granting hydrophobic and flame retardant properties to fabrics. As part of this study, three silanes with alkoxy groups, phosphoric acid esters, and fluorinated groups were synthesized. Cotton fabrics were modified with obtained compounds and then their fire- and waterproofing effect was examined.

\section{Materials and Methods}

The fabric used has a $145 \mathrm{~g} / \mathrm{m}^{2}$ surface weight and was made in $100 \%$, bleached before the modification process in a hydrogen peroxide bath cotton fabric. Tetraethoxysilane, triethoxysilane, octafluoropentanol were obtained from "Unisil" (Tarnów, Poland). Other reagents and solvents were purchased from Aldrich (Poznan, Poland) and used without any additional preparatory steps. 


\subsection{Synthesis of Organosilicon Flame Retardant Compounds}

The synthesis of three types of organosilicon flame retardant compounds has been developed by our research group and has not been published previously.

2.1.1. Synthesis of Organosilicon Derivatives of Fluorinated Phosphoric Esters (1 and 2)

The syntheses were carried out according to Scheme 1.<smiles>C=CCc1ccc(OP(=O)(Cl)Oc2ccc(CC=C)cc2OC)c(OC)c1</smiles><smiles>[R]OP(=O)(Oc1ccc(CC=C)cc1OC)Oc1ccc(CC=C)cc1OC</smiles><smiles>[R]OP(=O)(Oc1ccc(CC=C)cc1OC)Oc1ccc(CC=C)cc1OC</smiles><smiles></smiles><smiles>[H][R]=C(F)C(F)(F)C(F)(F)C(F)(F)CC</smiles>

1<smiles>[AlH2]</smiles><smiles>Cc1c(F)c(F)c(F)c(F)c1F</smiles>

Scheme 1. Synthesis of organosilicon derivatives of fluoroalkyl phosphoric esters (1 and 2).

In a round-bottom flask equipped with a reflux condenser, a dropping funnel, a thermometer, and magnetic stirrer eugenol $(60 \mathrm{~mL} ; 0.38 \mathrm{~mol})$, toluene $(50 \mathrm{~mL})$ and pyridine $(30 \mathrm{~mL} ; 0.38 \mathrm{~mol})$ were placed, then the system was cooled to $0{ }^{\circ} \mathrm{C}$. Next $\mathrm{POCl}_{3}(17.5 \mathrm{~mL}$; $0.19 \mathrm{~mol}$ ) was slowly added while maintaining the temperature below $10^{\circ} \mathrm{C}$. After the addition of the whole amount of $\mathrm{POCl}_{3}$, the system was kept at $0{ }^{\circ} \mathrm{C}$ for $2 \mathrm{~h}$. After this time, the reaction mixture was allowed to stand overnight at room temperature. The resulting pyridine hydrochloride was then filtered off (precipitate was washed with toluene) and another portion of pyridine $(20 \mathrm{~mL}, 0.24 \mathrm{~mol})$ was added. The system was again cooled to $0{ }^{\circ} \mathrm{C}$ and octafluoropentyl alcohol $(26.5 \mathrm{~mL} ; 0.19$ mol一to obtain compound $\mathbf{1})$ or pentafluorophenol ( $20 \mathrm{~mL} ; 0.19 \mathrm{~mol}$ ) dissolved in $10 \mathrm{~mL}$ of toluene (to obtain compound 2) were slowly added while maintaining the temperature below $10^{\circ} \mathrm{C}$. After the addition of the alcohol (or phenol), the temperature was kept at $0{ }^{\circ} \mathrm{C}$ for $2 \mathrm{~h}$. After this time, the reaction mixture was allowed to stand overnight at room temperature, and then the mixture was subjected to filtration and excess of pyridine was evaporated under reduced pressure. In the next step, the obtained mid product $(0.17 \mathrm{~mol})$, toluene $(50 \mathrm{~mL})$, triethoxysilane 
(38 mL; $0.2 \mathrm{~mol})$ and $2 \%$ Karstedt catalyst solution $\left(21.5 \mu \mathrm{L} ; 1.88 \times 10^{-6} \mathrm{~mol}\right.$ of Pt) were placed together in a round-bottomed flask equipped with a thermometer, reflux condenser, and magnetic stirrer. The reaction was carried out at $90{ }^{\circ} \mathrm{C}$ for $2 \mathrm{~h}$. Then, the excess of triethoxysilane was evaporated under reduced pressure. The colorless liquids were obtained with a yield of $85 \%$ and $83 \%$, respectively.

The compound $\mathbf{1}$ :

${ }^{1} \mathrm{H}$ NMR $\left(\mathrm{C}_{6} \mathrm{D}_{6}, 298 \mathrm{~K}, 300 \mathrm{MHz}\right)$ ppm: 1.13-1.23 (Si-O- $\left.\mathrm{CH}_{2}-\mathrm{CH}_{3}, \mathrm{Si}_{-}-\mathrm{CH}_{2}-\mathrm{CH}_{2}-\right) ; 3.08$ $\left(\mathrm{t}, \mathrm{CH}_{2}\right) ; 3.43\left(\mathrm{~s},-\mathrm{O}-\mathrm{CH}_{3}\right) ; 3.86\left(\mathrm{q}, \mathrm{Si}-\mathrm{O}-\mathrm{CH}_{2}-\mathrm{CH}_{3}\right) ; 5.32\left(\mathrm{t},-\mathrm{P}-\mathrm{O}-\mathrm{CH}_{2}-\mathrm{CF}_{2}-\right) ; 5.63\left(\mathrm{t},-\mathrm{CF}_{2} \mathrm{H}\right)$; 6.54-6.85 (CH phenyl).

${ }^{13} \mathrm{C}$ NMR $\left(\mathrm{C}_{6} \mathrm{D}_{6}, 298 \mathrm{~K}, 75.5 \mathrm{MHz}\right) \mathrm{ppm}: 15.8\left(\mathrm{Si}-\mathrm{CH}_{2}-\mathrm{CH}_{2}-\right) ; 17.9\left(\mathrm{Si}-\mathrm{O}-\mathrm{CH}_{2}-\mathrm{CH}_{3}\right)$; $23.2\left(\mathrm{Si}-\mathrm{CH}_{2}-\mathrm{CH}_{2}-\right) ; 40.1\left(-\mathrm{CH}_{2}-\right)$; $55.6\left(-\mathrm{O}-\mathrm{CH}_{3}\right) ; 60.3\left(\mathrm{Si}-\mathrm{O}-\mathrm{CH}_{2}-\mathrm{CH}_{3}\right) ; 113.5-150.8$ (phenyl). ${ }^{29} \mathrm{Si}$ NMR $\left(\mathrm{C}_{6} \mathrm{D}_{6}, 298 \mathrm{~K}, 59 \mathrm{MHz}\right) \mathrm{ppm}:-89.2$

${ }^{31} \mathrm{P}$ NMR $\left(\mathrm{C}_{6} \mathrm{D}_{6}, 298 \mathrm{~K}, 59 \mathrm{MHz}\right) \mathrm{ppm}:-1.3$

The compound 2 :

${ }^{1} \mathrm{H}$ NMR $\left(\mathrm{C}_{6} \mathrm{D}_{6}, 298 \mathrm{~K}, 300 \mathrm{MHz}\right) \mathrm{ppm}: 1.07-1.19\left(\mathrm{Si}-\mathrm{O}-\mathrm{CH}_{2}-\mathrm{CH}_{3}, \mathrm{Si}-\mathrm{CH}_{2}-\mathrm{CH}_{2}-\right) ; 3.12$ $\left(\mathrm{t}, \mathrm{CH}_{2}\right) ; 3.39$ (s, $\left.-\mathrm{O}-\mathrm{CH}_{3}\right) ; 3.84$ (q, Si-O-CH$\left.{ }_{2}-\mathrm{CH}_{3}\right) ; 6.54-7.33(\mathrm{CH}$ phenyl).

${ }^{13} \mathrm{C}$ NMR $\left(\mathrm{C}_{6} \mathrm{D}_{6}, 298 \mathrm{~K}, 75.5 \mathrm{MHz}\right) \mathrm{ppm}: 15.8\left(\mathrm{Si}-\mathrm{CH}_{2}-\mathrm{CH}_{2}-\right) ; 17.9\left(\mathrm{Si}-\mathrm{O}-\mathrm{CH}_{2}-\mathrm{CH}_{3}\right)$; $23.2\left(\mathrm{Si}-\mathrm{CH}_{2}-\mathrm{CH}_{2}-\right) ; 40.1\left(-\mathrm{CH}_{2}-\right) ; 55.6\left(-\mathrm{O}-\mathrm{CH}_{3}\right) ; 60.3\left(\mathrm{Si}-\mathrm{O}-\mathrm{CH}_{2}-\mathrm{CH}_{3}\right) ; 113.5-150.8$ (phenyl). ${ }^{29} \mathrm{Si} \mathrm{NMR}\left(\mathrm{C}_{6} \mathrm{D}_{6}, 298 \mathrm{~K}, 59 \mathrm{MHz}\right) \mathrm{ppm}:-90.1$

${ }^{31} \mathrm{P}$ NMR $\left(\mathrm{C}_{6} \mathrm{D}_{6}, 298 \mathrm{~K}, 59 \mathrm{MHz}\right) \mathrm{ppm}:-1.2$

2.1.2. Synthesis of Organosilicon Derivative of Phosphoric Diesters (3)

The synthesis was carried out according to Scheme 2.<smiles>C=CCOCC1COP(=O)(OP2(=O)OCC(COC/C=C/C(C)(C)C)O2)O1</smiles>

Scheme 2. Synthesis of organosilicon derivative of phosphoric diesters (3).

The synthesis of compound 3 was carried out analogously to the synthesis described in Section 2.1.1. The 3-allyloxy-1,2-propanediol ( $20.8 \mathrm{~mL} ; 0.19 \mathrm{~mol})$ was used instead of eugenol, while water $(1.7 \mathrm{~mL} ; 0.19 \mathrm{~mol}$ ) was added instead of octafluoropentanol (or pentafuorophenol). The product was obtained with a yield of $83 \%$.

${ }^{1} \mathrm{H}$ NMR $\left(\mathrm{C}_{6} \mathrm{D}_{6}, 298 \mathrm{~K}, 300 \mathrm{MHz}\right) \mathrm{ppm}$ : 0.93-1.14 ( $\left.\mathrm{Si}-\mathrm{O}-\mathrm{CH}_{2}-\mathrm{CH}_{3}, \mathrm{Si}-\mathrm{CH}_{2}-\mathrm{CH}_{2}-\right)$; 3.49-4.51 ( $\left.\mathrm{Si}-\mathrm{O}-\mathrm{CH}_{2}-\mathrm{CH}_{3},-\mathrm{O}-\mathrm{CH}_{2-}, \mathrm{O}-\mathrm{CH}-\right)$.

${ }^{13} \mathrm{C}$ NMR $\left(\mathrm{C}_{6} \mathrm{D}_{6}, 298 \mathrm{~K}, 75.5 \mathrm{MHz}\right)$ ppm: 11.5( $\left.\mathrm{Si}-\mathrm{CH}_{2}-\mathrm{CH}_{2}-\right) ; 16.8\left(\mathrm{Si}-\mathrm{O}-\mathrm{CH}_{2}-\mathrm{CH}_{3}\right) ; 23.7$ ( $\mathrm{Si}-\mathrm{CH}_{2}-\mathrm{CH}_{2}$ ); 59.1 (Si-O- $\left.\mathrm{CH}_{2}-\mathrm{CH}_{3}\right) ; 69.3-74.1$ (-O- $\left.\mathrm{CH}_{2-}^{-},-\mathrm{O}-\mathrm{CH}-\right)$.

${ }^{29} \mathrm{Si} \mathrm{NMR}\left(\mathrm{C}_{6} \mathrm{D}_{6}, 298 \mathrm{~K}, 59 \mathrm{MHz}\right) \mathrm{ppm}:-81.4$

${ }^{31} \mathrm{P}$ NMR $\left(\mathrm{C}_{6} \mathrm{D}_{6}, 298 \mathrm{~K}, 59 \mathrm{MHz}\right) \mathrm{ppm}:-1.9$ 


\subsection{Modification of Fabrics}

Cotton fabrics were modified in two ways. In the one-step process, the bleached fabrics were impregnated with solutions of fire-retardant compounds 1, 2, 3 or in the two-step process the fabrics were initially mercerized.

2.2.1. Cotton Fabric Impregnation with Organosilicon Flame Retardant Compounds (1, 2, and 3)

In a round-bottom flask $5 \mathrm{vol} . \%$ of isopropanolic solution of organosilicon flame retardant compound $(1,2$, or 3$)$ were placed; moreover, 5 vol. $\%$ of acetic acid and 5 vol. $\%$ of water were placed to the solution and hydrolysis were conduct for one hour at room temperature. The flask was equipped with a reflux condenser and a magnetic stirrer. The hydrolyzed solution was then transferred to laboratory trays where the fabrics were modified for half an hour. Then, the samples were squeezed and next dried for $60 \mathrm{~min}$ at $80^{\circ} \mathrm{C}$ and cured for $3 \mathrm{~min}$ at $130^{\circ} \mathrm{C}$.

\subsubsection{Mercerization Process (M)}

A $10 \% \mathrm{NaOH}$ solution was prepared and then the bleached fabrics were soaked in it for $10 \mathrm{~min}$. The fabrics were then rinsed intensively in water and dried.

\subsubsection{Washing Process}

The modified fabrics were washed five times for $30 \mathrm{~min}$ at $40{ }^{\circ} \mathrm{C}$ according to the standard [39].

\subsection{Analyses and Measurements}

\subsubsection{NMR Spectroscopy}

To make the ${ }^{13} \mathrm{C}$ and ${ }^{1} \mathrm{H}$ NMR spectra, a Bruker Ultrashield $300 \mathrm{MHz}$ spectrometer (Bruker, Billerica, MA, USA) was used and the ${ }^{31} \mathrm{P}$ and ${ }^{29} \mathrm{Si}$ spectra were recorded on a Bruker Ascend 400 spectrometer (Bruker, Billerica, MA, USA). A $\mathrm{CDCl}_{3}$ solvent was used to make all spectra.

\subsubsection{Determination of the Amount of Modifiers Applied on Fabrics (Add-on)}

The add-on value of cotton samples (A) was calculated according to the Equation (1). Where $(W i)$ was weighing a sample before washing and $(W f)$ was weighing a sample after washing. Analytical balance Ohaus PX224M/1 (OHAUS Europe GmbH, Nänikon, Switzerland) was used in the measurements.

$$
A=\frac{W f-W i}{W i} * 100
$$

\subsubsection{Elemental Analysis of Coated Samples}

The SEM-EDS (Scanning Electron Microscopy with Energy Dispersive Spectroscopy) technique was employed to determine the concentration of the $\mathrm{C}, \mathrm{O} F, \mathrm{Si}$ and $\mathrm{P}$ atoms on the surface of prepared cotton samples. Measurements were made using a Hitachi S-3500N (Hitachi Scientific Instruments, Schaumburg, IL, USA) (manufacturer, city, state, country) scanning electron microscope (SEM) equipped with a Thermo Scientific energy-dispersive X-ray detector (EDS) (Hitachi Scientific Instruments, Schaumburg, IL, USA).

\subsubsection{Microscale Combustion Calorimetry (MCC)}

The flammability was assessed using a Pyrolysis-Combustion Flow Calorimeter (PCFC) produced by Fire Testing Technology Ltd. (East Grinstead, UK) West Susexx, (FTT). The heating rate $(\beta)$ was $1{ }^{\circ} \mathrm{C} / \mathrm{s}$, the pyrolysis temperature range $75-750{ }^{\circ} \mathrm{C}$, and the combustion temperature $900{ }^{\circ} \mathrm{C}$. The flow was a mixture of $\mathrm{O}_{2} / \mathrm{N}_{2} 20 / 80 \mathrm{~cm}^{3} / \mathrm{min}$ and the sample weight 5-6 $\pm 0.01 \mathrm{mg}$. All measurements were repeated three times and the experimental error on HRR (heat release rate) was $\pm 2 \%$ and the instrumental error on $\mathrm{T}$ was $1{ }^{\circ} \mathrm{C}$ and $\mathrm{t}$ was $1 \mathrm{~s}$. 


\subsubsection{Limiting Oxygen Index}

The limiting oxygen index (LOI) were determined according to the standard [40]. Each fabric was tested three times and the mean value of the measurements was calculated. The experimental error was $\pm 0.5 \%$.

\subsubsection{Thermogravimetric Analysis}

Thermogravimetric analysis (TGA) of samples (9-10 $\mathrm{mg}$ ) was evaluated using a TA Instruments Q50 TGA (TA Instruments, New Castle, DE, USA) thermobalance at a linear heating rate of $10{ }^{\circ} \mathrm{C} / \mathrm{min}$ from room temperature to $700{ }^{\circ} \mathrm{C}$ under synthetic air (60 mL/min). The experimental error was $0.5 \%$ on weight and $1{ }^{\circ} \mathrm{C}$ on temperature.

\subsubsection{Studies of Surface Morphology}

Surface morphologies of modified and unmodified samples were evaluated using Hitachi S-3400N scanning electron microscope (SEM) (Hitachi Scientific Instruments, Schaumburg, IL, USA). The samples were coated with a thin layer of gold before performing observations.

\subsubsection{Water Contact Angle (WCA) Measurements}

The water contact angles (WCA) were measured using an automatic video contactangle testing apparatus Krüss model DSA 100 Expert (Kruss, Hamburg, Germany). A $10 \mu \mathrm{L}$ volume of water was applied onto the treated cotton fabrics. Each result is an average from the measurements of five drops. The experimental error was $\pm 2 \%$.

\section{Results and Discussion}

The synthesis of three new organosilicon flame retardant compositions was carried out in three steps. In the first and second steps, phosphororganic or fluorinated phosphororganic compounds have been synthesized, while in the third step the hydrosilylation with triethoxysilane was performed (Schemes 1 and 2).

All the obtained derivatives (1-3) contained alkoxysilyl groups susceptible to hydrolysis and condensation processes enabling their permanent binding to the substrate (cotton fibers). However, considering that all the derivatives (1-3) obtained have three alkoxysilyl groups, binding to the cotton is possible (for sterical reasons) only through one or two groups. The remaining groups condense together to form a siloxane layer on the surface of the modified fibers. In fact, partial condensation of the ethoxysilyl groups can be observed already during the isolation of products (1-3), which is confirmed by NMR analysis (especially ${ }^{29} \mathrm{Si}$ ). This partial condensation of compounds promotes the formation of fire-resistant coatings on the surface of modified fabrics. Thus, the observed pre-condensation effect is advantageous because it is possible to form a sealed fireproof coating on the surface of the modified fabrics. A lot of studies have been carried out to confirm the effect of condensation on the formation of a protective layer on the surface of the fibers and the improvement of flame-retardant properties [20,41,42]. In addition, our previous research has shown that as a result of condensation in the sol-gel process, a siloxane layer is formed which improves the fireproof effect $[35,36]$.

The samples of bleached cotton fabrics were modified with both described compositions by pad dry cure method. At two-step processes, samples were subjected to the mercerization process before actual impregnation with obtained prepolymer solutions. The mercerization was carried out to facilitate the attachment of the modifier by activation of the surface of the textiles and to increase the number of hydroxyl groups capable to create covalent bonds with triethoxysilyl groups of organosilicon flame retardant compounds. All samples have been weighed before and after their modification. The add-on value was calculated on this basis (Table 1 ). 
Table 1. Add-on values of modified samples.

\begin{tabular}{cccc}
\hline Symbol & $\mathbf{1}$ & $\mathbf{2}$ & $\mathbf{3}$ \\
\hline One-step process & $8.3 \%$ & $8.3 \%$ & $8.1 \%$ \\
Two-step process (M) & $9.8 \%$ & $9.9 \%$ & $9.5 \%$ \\
\hline
\end{tabular}

The data presented in Table 1 show that the value of add-on is at a similar level, regardless of the modifiers used. Fabrics modified with fluorinated phosphoric esters have a slightly higher add-on value due to the higher molecular weight. Furthermore, it can be seen that the cotton mercerization (applied in case of two-step impregnation process) resulted in an increased add-on value of all mercerized samples compared to those modified in a single-step process. It is worth noting that by applying a $5 \%$ solution of the modifier all of the add-ons are relatively low. Thanks to this, the modified fabrics retained their elasticity, soft-grip, and visual qualities. In some studies, to obtain a good fire retardant effect, it was necessary to use very high concentrations of modifiers, which had an impact on the high value of add-on (even 30\%) [31].

Cotton samples impregnated with the obtained solutions in a single or two-stage process before and after washing were subjected to thermogravimetric analysis in the air atmosphere to assess the influence of applied modifications on the thermal stability of the fabric and durability of the impregnation. To facilitate the analysis and comparison of recorded TG curves presented in Figures 1-4, the results of the TG and DTG analysis of impregnated samples including their temperatures of $1,5,10$, and $20 \%$ mass loss (at which the tested samples lost 1,5,10, and $20 \%$ of their initial mass), temperatures of maximum decomposition rate (Tmax), measured decomposition rates at $\operatorname{Tmax}(\Delta \mathrm{m})$, as well as residue yields observed at Tmax and $700{ }^{\circ} \mathrm{C}$, were presented in Table 2 and compared with the results obtained for unmodified cotton as a reference.
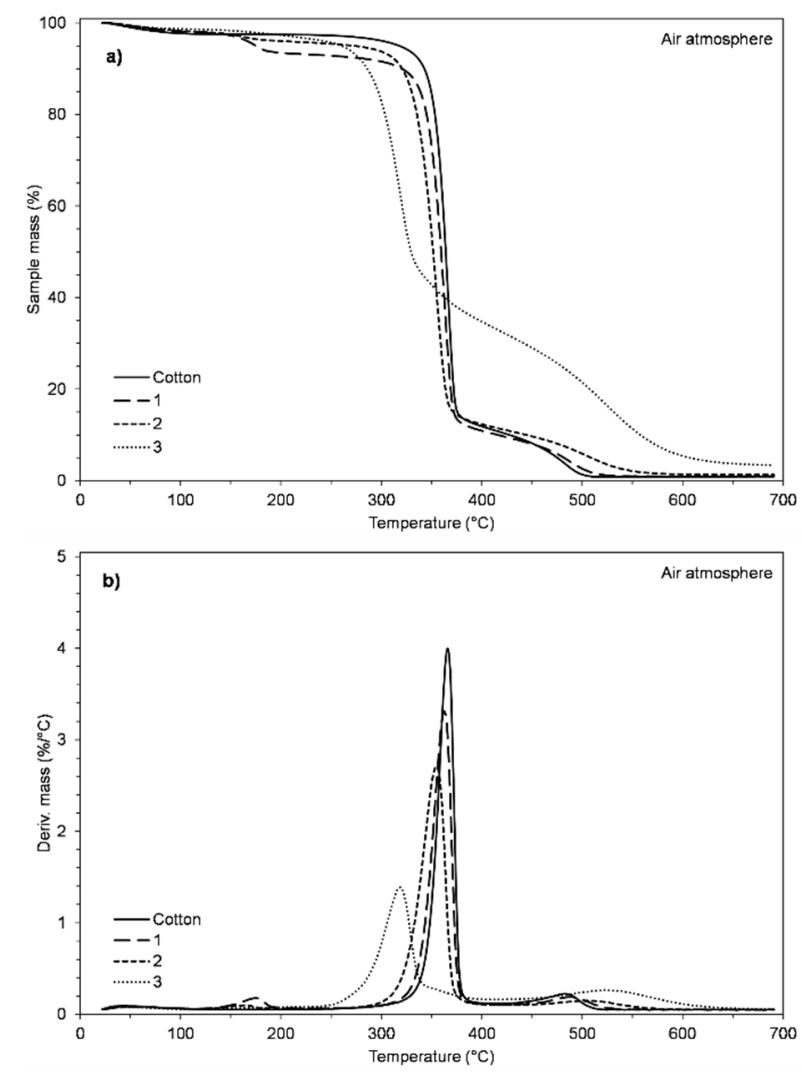

Figure 1. TG (a) and DTG (b) curves of cotton samples impregnated in a single-step process. 

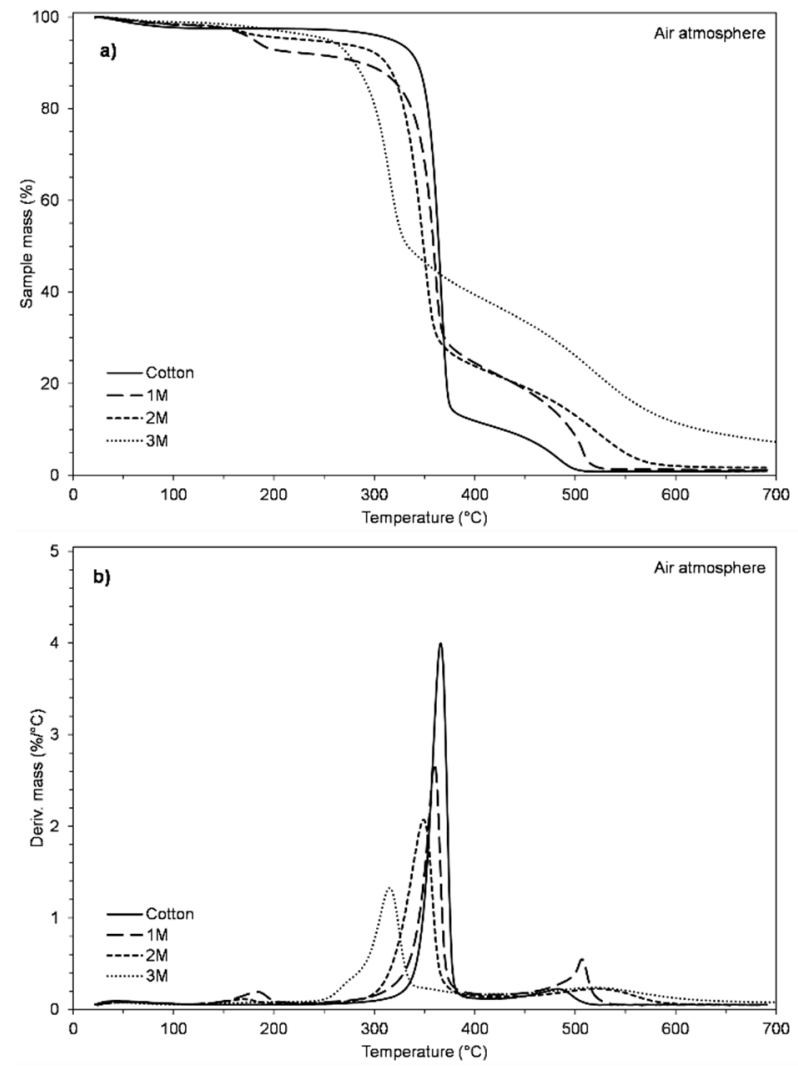

Figure 2. TG (a) and DTG (b) curves of cotton samples impregnated in a two-step process.
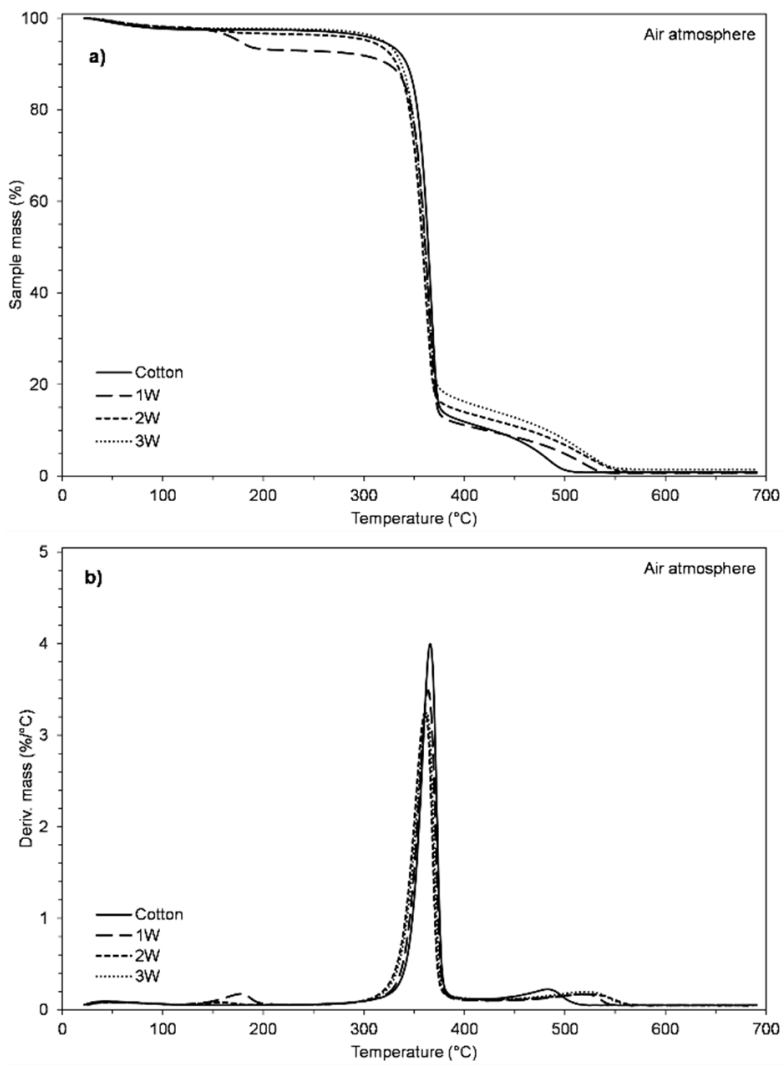

Figure 3. TG (a) and DTG (b) curves of cotton samples impregnated in a single-step process after washing. 

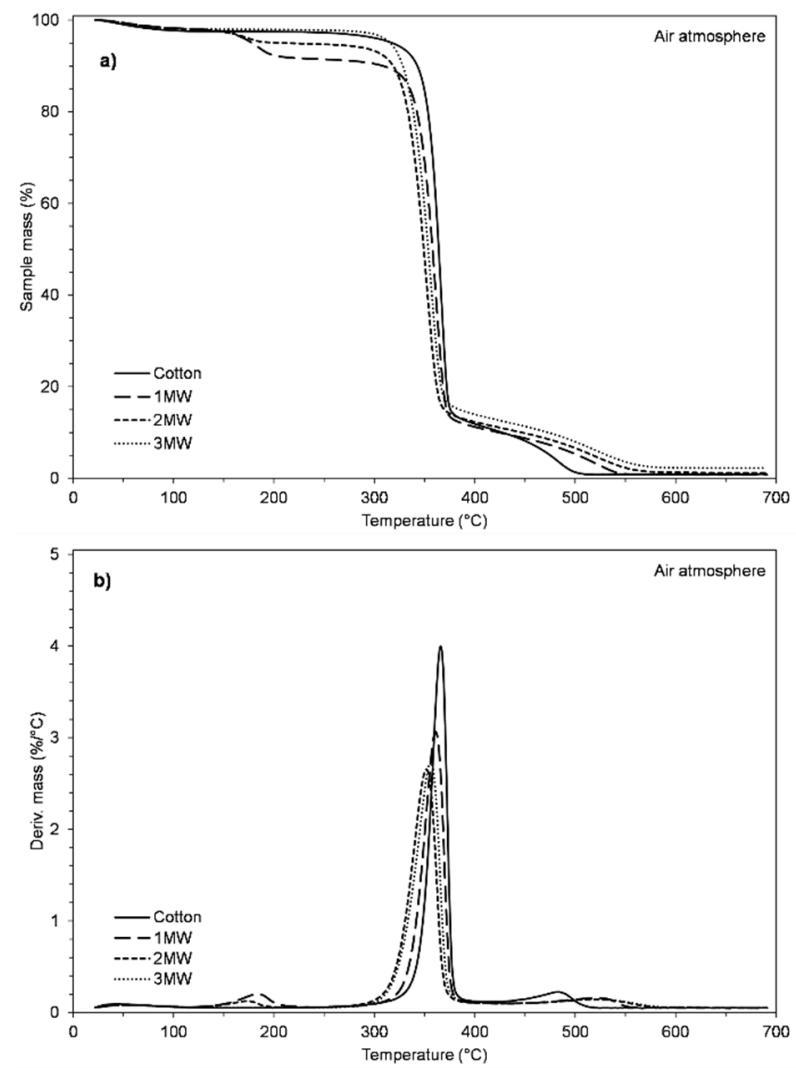

Figure 4. TG (a) and DTG (b) curves of cotton samples impregnated in a two-step process after washing.

Table 2. Results of TG and DTG analyzes.

\begin{tabular}{|c|c|c|c|c|c|c|c|c|}
\hline \multirow[b]{2}{*}{ Sample } & \multicolumn{4}{|c|}{ Mass Loss Temperature $\left({ }^{\circ} \mathrm{C}\right)$} & \multirow{2}{*}{$\underset{\left({ }^{\circ} \mathrm{C}\right)}{\operatorname{Tmax}}$} & \multirow{2}{*}{$\begin{array}{c}\Delta \mathrm{m}^{\mathrm{b}} @ \\
\operatorname{Tmax}(\% \\
\left.{ }^{\circ} \mathrm{C}^{-1}\right)\end{array}$} & \multicolumn{2}{|c|}{ Residue (\%) } \\
\hline & $1 \%$ & $5 \%$ & $10 \%$ & $20 \%$ & & & $\begin{array}{c}\stackrel{@}{\operatorname{Tmax}} \\
\text { (a) }\end{array}$ & $@ 700{ }^{\circ} \mathrm{C}$ \\
\hline Cotton & 51.8 & 318 & 342.9 & 353.3 & 366.1 & 3.95 & 41.9 & 0.92 \\
\hline 1 & 61.4 & 175.1 & 320.5 & 344.9 & 362.4 & 3.26 & 40.2 & 0.96 \\
\hline 2 & 65.5 & 273.8 & 320.8 & 335.5 & 354.7 & 2.67 & 41.7 & 1.28 \\
\hline 3 & 70.7 & 260.6 & 286.1 & 303.7 & 318.8 & 1.34 & 62.6 & 3.37 \\
\hline $1 \mathrm{M}$ & 65.7 & 180.3 & 287.6 & 337 & 359.8 & 2.64 & 47.4 & 1.19 \\
\hline $2 \mathrm{M}$ & 68.6 & 232.6 & 311.5 & 329.4 & 349.1 & 2.02 & 49.6 & 1.68 \\
\hline $3 \mathrm{M}$ & 87.2 & 254.7 & 280.2 & 301.2 & 315.2 & 1.28 & 65.1 & 7.27 \\
\hline $1 \mathrm{~W}$ & 59.8 & 176.3 & 324.2 & 347.6 & 363.8 & 3.44 & 41.1 & 0.67 \\
\hline $2 \mathrm{~W}$ & 62.5 & 305.7 & 332.8 & 345.3 & 361 & 3.2 & 42 & 0.92 \\
\hline $3 W$ & 57.6 & 319.8 & 337.4 & 348 & 362.8 & 3.2 & 43.3 & 1.47 \\
\hline $1 \mathrm{MW}$ & 64.1 & 178.3 & 308.8 & 342.3 & 361.2 & 3.01 & 40 & 0.77 \\
\hline $2 \mathrm{MW}$ & 61.3 & 207.3 & 318.6 & 333.4 & 351.7 & 2.6 & 43.5 & 1.18 \\
\hline $3 \mathrm{MW}$ & 61.7 & 315.8 & 328.3 & 338.6 & 356.1 & 2.68 & 43.1 & 2.23 \\
\hline
\end{tabular}

a Tmax-temperature of maximum decomposition rate, ${ }^{\mathrm{b}} \Delta \mathrm{m}$-decomposition rate at Tmax. The experimental error was $0.5 \%$ on weight and $1{ }^{\circ} \mathrm{C}$ on temperature.

Based on the obtained TGA results (Table 2) and the course of the TG and DTG curves of cotton samples impregnated in a single-step process (Figure 1), it can be observed that the impregnation process resulted in a decrease in the thermal stability of the tested samples, regardless of the kind of the modification used, compared to pure cotton. In the case of samples 1 and 2, this was manifested by the appearance of an additional decomposition step in the temperature range $150-200{ }^{\circ} \mathrm{C}$, most likely due to the partial breakdown of the C$\mathrm{F}$ bonds present in the structure of applied impregnates and the release of HF. For all tested 
samples $(1,2$, and 3$)$, the $\mathrm{T}_{\text {onset }}$ temperature of the beginning of the main decomposition step measured as the intersection of the mass baseline and the tangent to the TG curve at the point of maximum rate of mass loss decreased from $335^{\circ} \mathrm{C}$ for neat cotton to 325 , 316 , and $280^{\circ} \mathrm{C}$ for samples 1,2 , and 3, respectively. At the same time, the change in the slope of the TG curves of the modified samples and the significant reduction in the intensity of the signals on their DTG curves presented in Figure 1b (especially for sample 3) indicate a reduction in the rate of main decomposition step related to the formation of volatiles, combustible and non-combustible species yielding aliphatic char in dehydration and cellulose depolymerization processes [43-45]. While for samples 1 and 2 no significant changes were observed in the char yield formed after the first decomposition step (at $380{ }^{\circ} \mathrm{C}$ ) compared to the reference sample, its yield produced during the degradation of sample 3 was significantly higher and amounted to $37 \%$ compared to $14 \%$ for the pure cotton sample. The impregnation of the samples with the obtained preparations also influenced the second stage of decomposition of the tested samples related to the conversion of aliphatic char into aromatic structures, with the slow evolution of water, methane, carbon mono and dioxide [36-38] by its spread-in-time compared to the reference sample. This is evidenced by the extension and flattening of the TG and DTG curves in the temperature range from 380 to $600{ }^{\circ} \mathrm{C}$. This effect is visible for sample 2 and especially sample 3 .

Subsequently, to evaluate the effect of the mercerization process on the impregnation efficiency samples impregnated in two-step process were also subjected the thermogravimetric analysis and its results were compared with those measured for cotton samples impregnated in single-step impregnation. The results of the TG and DTG analysis of 1M, $2 \mathrm{M}$, and $3 \mathrm{M}$ samples showed a further reduction in the temperatures of the beginning of the first stage of decomposition by about 5 to $10{ }^{\circ} \mathrm{C}$, a further reduction in the rate of the first decomposition stage and an increase in the char yield formed after the first decomposition step, and a significant spread in time of the second decomposition step, compared to the not mercerized samples. It was especially pronounced for samples $1 \mathrm{M}$ and $2 \mathrm{M}$ (char yield higher by about $10 \%$ ).

To assess the effect of the impregnation method on the durability of protective coatings obtained cotton samples impregnated in single and two-step process and subjected to the five-time washing were also subjected the thermogravimetric analysis and its results were compared with those measured for cotton samples impregnated in single or two-step impregnation before washing. The results presented in Figure 3 showed that the repeated washing process clearly weakens the observed effects. This is the result of the partial leaching of the applied coatings as a result of hydrolysis of the C-O-Si bonds formed during impregnation between cellulose and silyl derivatives of phosphate esters, which is also evidenced by the change in weight of the washed samples compared to freshly impregnated ones. Nevertheless, the course of the TG and DTG curves of the 1W, 2W, and $3 \mathrm{~W}$ samples differ from those of pure cotton. An additional decomposition step in the temperature range of $150-200{ }^{\circ} \mathrm{C}$ is still clearly observed, as well as a reduction in the decomposition rate of the discussed samples in the first and second stage, illustrated by a decrease in the intensity of the DTG curves peak in Figure $3 b$ and the flattening of the TG curves in the temperature range $380-600^{\circ} \mathrm{C}$ (Figure 3a).

As mentioned above, the use of the two-stage impregnation process improved its efficiency. This effect is also confirmed by the results of TG and DTG analyzes of 1MW, $2 \mathrm{MW}$, and $3 \mathrm{MW}$ samples subjected to two-stage impregnation and multiple washing processes, shown in Figure 4. Although the changes in the course of the curves compared to these of reference sample are not as clear as in the case of their counterparts before washing, as a result of the previously mentioned partial degradation of C-O-Si bonds, they are still significantly more pronounced than in the case of samples impregnated without the mercerization process after washing. The reduction of the maxima on the DTG curves in the range of $300-400^{\circ} \mathrm{C}$ and their shift towards lower temperatures (Figure $4 \mathrm{~b}$ ) as well as the spread overtime of the second decomposition stage of in the temperature range $380-600{ }^{\circ} \mathrm{C}$ (Figure $4 \mathrm{a}, \mathrm{b}$ ) are much clearer. For better understanding of the applied impregnation 
method and modifier structure effect on the thermal stability of measured samples and the durability of obtained coatings, additional plots showing the superimposed TG and DTG curves of cotton samples impregnated with all modifiers $(1,2$, and 3$)$ in a single and two-stage process before and after washing were presented in the supplementary materials file for the manuscript (Figures S1-S3).

Subsequently, all prepared samples of bleached cotton fabric (raw and modified in single and two-step impregnation) before and after the washing process were subjected to pyrolysis-combustion flow calorimetry (PCFC) measurements to assess the flame retardancy of the fabricated coatings. The obtained results of PCFC analysis are summarized in Table 3 where 1, 2, 3-type of modifier (Schemes 1 and 2), M-mercerization process, $\mathrm{W}$-washing process.

Table 3. Results of MCC analysis.

\begin{tabular}{|c|c|c|c|c|c|}
\hline Sample & $\mathrm{ttI}(\min )$ & $\mathrm{T}_{\text {PHRR }}\left({ }^{\circ} \mathrm{C}\right)$ & $\begin{array}{c}P_{\text {HRR }} \\
\left(W \cdot g^{-1}\right)\end{array}$ & $\begin{array}{c}\text { THR } \\
\left(\mathbf{k J} \cdot \mathrm{g}^{-1}\right)\end{array}$ & $\Delta$ THR (\%) \\
\hline Cotton & 330.0 & 392.4 & 270.3 & 12.1 & - \\
\hline 1 & 255.5 & 316.9 & 106.3 & 6.6 & 45.9 \\
\hline 2 & 256.0 & 317.4 & 112.0 & 6.7 & 45.0 \\
\hline 3 & 303.0 & 364.9 & 203.4 & 11.8 & 2.6 \\
\hline $1 \mathrm{M}$ & 247.5 & 308.8 & 70.2 & 5.7 & 52.9 \\
\hline $2 \mathrm{M}$ & 243.0 & 304.3 & 73.7 & 6.9 & 43.0 \\
\hline $3 \mathrm{M}$ & 297.5 & 359.3 & 141.5 & 8.6 & 29.0 \\
\hline $1 \mathrm{~W}$ & 284.0 & 345.7 & 166.0 & 9.4 & 22.4 \\
\hline $2 W$ & 292.5 & 354.2 & 169.0 & 10.0 & 17.2 \\
\hline $3 W$ & 315.0 & 377.1 & 227.9 & 10.7 & 12.0 \\
\hline $1 \mathrm{MW}$ & 283.0 & 344.7 & 149.7 & 9.4 & 22.9 \\
\hline $2 \mathrm{MW}$ & 299.5 & 361.3 & 154.3 & 9.9 & 18.5 \\
\hline $3 \mathrm{MW}$ & 301.0 & 362.8 & 171.6 & 10.0 & 17.7 \\
\hline
\end{tabular}

The experimental error on HRR was $\pm 2 \%$ and the instrumental error on $\mathrm{T}$ was $1^{\circ} \mathrm{C}$ and $\mathrm{t}$ was $1 \mathrm{~s}$.

Results of the PCFC analysis obtained for cotton fabric samples modified with all preparations in a single and two-step processes influenced the reduction of the cotton textile flammability compared to the raw fabric as reference. The flame retardant effect of modified fabrics depended strongly on the structure of the compound used as well as the impregnation process applied.

As can be seen in Figure 5a and Table 3. temperatures of maximum heat release rate ( $\left.\mathrm{T}_{\mathrm{PHRR}}\right)$ of all measured samples $(1,2$ and 3$)$ were shifted toward lower temperatures form $392{ }^{\circ} \mathrm{C}$ for raw cotton textile to about $317{ }^{\circ} \mathrm{C}$ for samples 1 and 2 and $365{ }^{\circ} \mathrm{C}$ for sample 3 with a simultaneous decrease in the value of maximum heat release rate $\left(\mathrm{P}_{\mathrm{HRR}}\right)$ from $270 \mathrm{~W} \cdot \mathrm{g}^{-1}$ to 106,112 and $203 \mathrm{~W} \cdot \mathrm{g}^{-1}$ for samples 1,2 , and 3, respectively. In the case of samples 1 and 2, the single-step impregnation resulted also in the significant (over $45 \%$ ) reduction in total heat release (THR) value form $12 \mathrm{~kJ} \cdot \mathrm{g}^{-1}$ observed for reference sample to about $6.5 \mathrm{~kJ} \cdot \mathrm{g}^{-1}$. THR value measured for sample 3 was almost unchanged compared to the raw cotton. This may be explained by the presence of two aromatic rings the structure of derivatives 1 and 2, as well as fluoroalkyl or fluorophenyl groups. It is well known that the presence of aromatic rings in compounds increases their thermal stability and promotes the formation of carbonaceous char during their decomposition, acting as an insulating surface layer. Thanks to this mechanism, heat conduction inside the sample is slowed down and the evolution of flammable gases is reduced. Charring is the most common mode of action in the condensed-phase [5,46,47]. From the other side, the presence of fluorinated groups in the structure of impregnates 1 and 2 also can influence the fire-retardant mechanism of the modifying compositions [5,46]. Halogen compounds disrupt the free radical mechanism during combustion, which is responsible for providing heat to continue this process. The halides react in the gas phase to form hydrohalides upon combustion, which form more stable and less reactive free radicals, thus reducing the 
amount of heat needed to maintain the flame and simultaneously reducing the amount of oxygen in the burning zone $[48,49]$. Another scenario of phosphorus-halide synergy involves the action of halides as a blowing agent to foam the yielded char rather than to operate in the gas phase as a free radical scavenger [50]. Regardless of the mechanism of phosphorus-halides synergy, the understanding of which was not the aim of this work and certainly requires more complex research the presence of fluorine atoms in the structure of derivatives 1 and 2 certainly effectively influenced their flame-retardant effect.
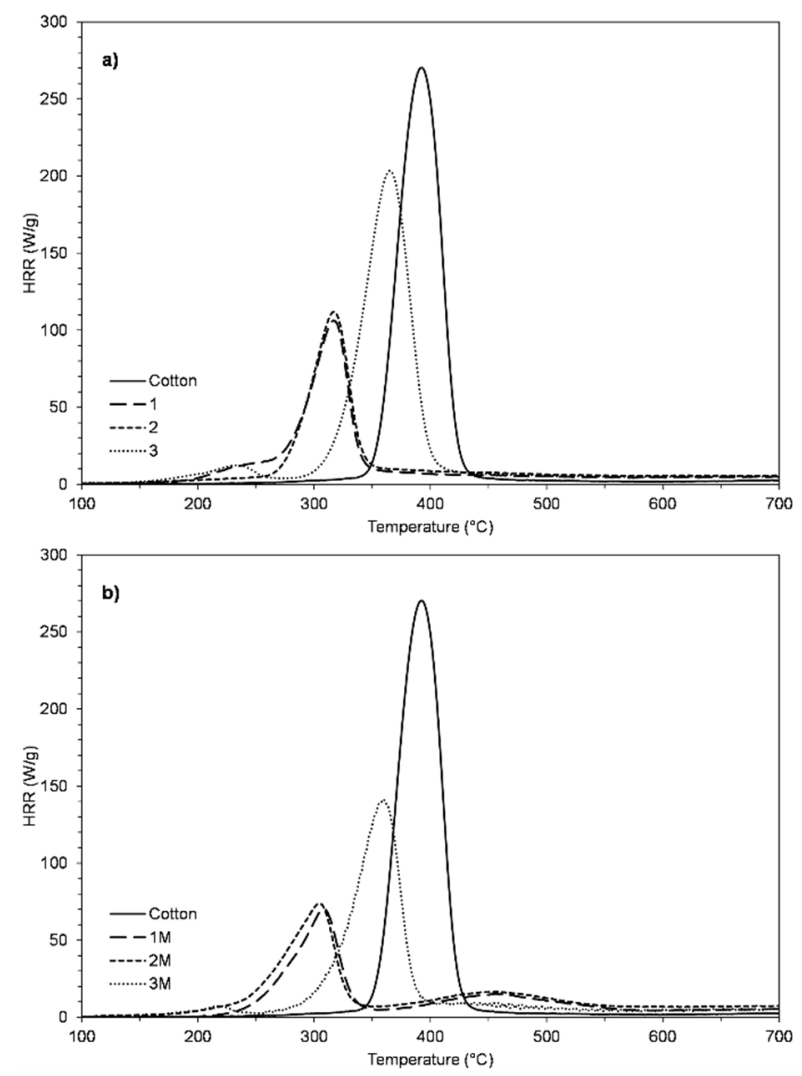

Figure 5. HRR curves of cotton fabric samples modified in a single (a) and two-step (b) process before washing.

Results of the PCFC analysis and the assumption of the occurrence of phosphorushalide synergy seem to be consistent with the results of TG analysis.

Similarly, the results of TG analysis and also the PCFC tests confirmed the positive effect of the mercerization process on the efficiency of cotton samples impregnation as a result of the cotton surface activation and increase in the number of active centers (hydroxyl groups) and subsequently the reduction of their flammability. As can be observed in Figure $5 \mathrm{~b}$. Above-mentioned trends (shift of the $\mathrm{T}_{\mathrm{PHRR}}$ toward lower values and decrease in $\mathrm{P}_{\text {HRR }}$ and THR values) are more pronounced for samples $1 \mathrm{M}, 2 \mathrm{M}$, and $3 \mathrm{M}$ subjected to the two-step impregnation. $\mathrm{T}_{\mathrm{PHRR}}$ temperatures were shifted to the 309,304 , and $359^{\circ} \mathrm{C}, \mathrm{P}_{\mathrm{HRR}}$ values were decreased to 70,73 and $142 \mathrm{Wg}^{-1}$ for $1 \mathrm{M}, 2 \mathrm{M}$, and $3 \mathrm{M}$ samples, respectively.

The shift of the $T_{P H R R}$ toward lower values and decrease in $P_{\text {HRR }}$ and THR values are favorable effects. This phenomenon is caused by the formation of char instead of flammable gases at lower temperatures, which results in the release of less energy. As a result of this process, less flammable gases and more residues were created, which lowered the flammability of fabrics.

To evaluate the durability of the coatings formed the samples subjected to the fivetime washing process were also tested by the PCFC technique. Results of the PCFC measurements of washed samples $1 \mathrm{~W}, 2 \mathrm{~W}$, and $3 \mathrm{~W}$ as well as their modified in two-step 
process analogs (1MW, 2MW, and, 3MW samples) are presented in Figure 6 as temperatureresolved heat release rate curves and in Table 3.
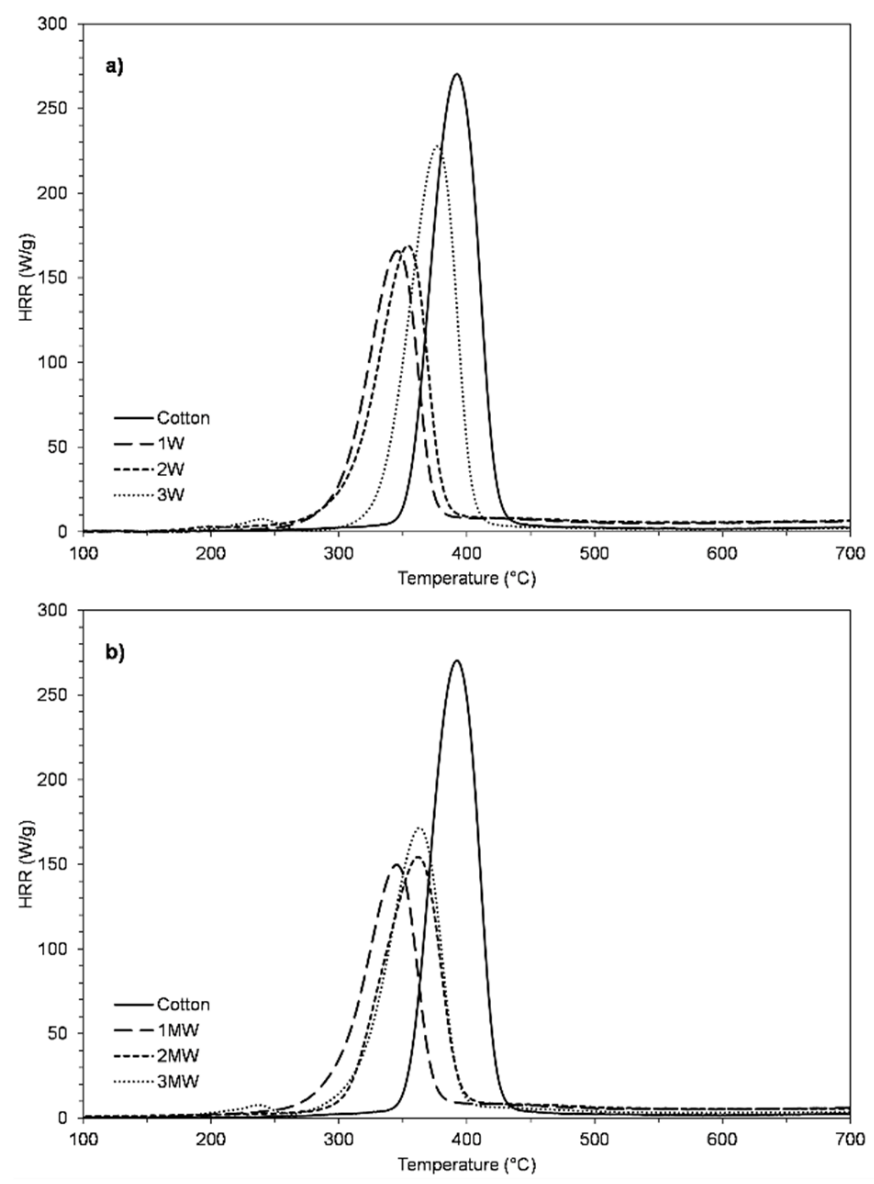

Figure 6. HRR curves of cotton fabric samples modified in a single (a) and two-step (b) process subjected to five washing cycles.

Although the partial deterioration of the flammability parameters may be observed after five-time washings due to the hydrolytic degradation of protective coatings the flame retardant properties were not completely lost and $\mathrm{T}_{\mathrm{PERR}}, \mathrm{P}_{\mathrm{HRR}}$, and THR indices for all samples were still better than those observed for the raw cotton sample. It can be also observed that mercerized fabrics modified in two-step process show lower flammability after five washes than their non-mercerized analogous. The better flame retardancy parameters observed for samples modified with compounds 1 and 2 subjected to the five washing cycles may be explained by the presence of fluorinated groups in the structure of compounds used for their impregnation. These substituents of a hydrophobic nature can protect the surface of modified textile against water and partially prevent leaching resulting from the hydrolysis of C-O-Si bonds between the modifier and cellulose. A similar effect was observed in the case of TG analysis. The lack of complete resistance to washing of the applied modifications is a disadvantage of the described process. Flame retardant fabric compositions should be wash resistant to effectively protect people and infrastructure from fire. However, scientists all over the world are struggling with this problem and it has not been successfully solved so far.

The limited oxygen index (LOI) was also determined for all modified fabrics. The measurement results are presented in Figure 7. 


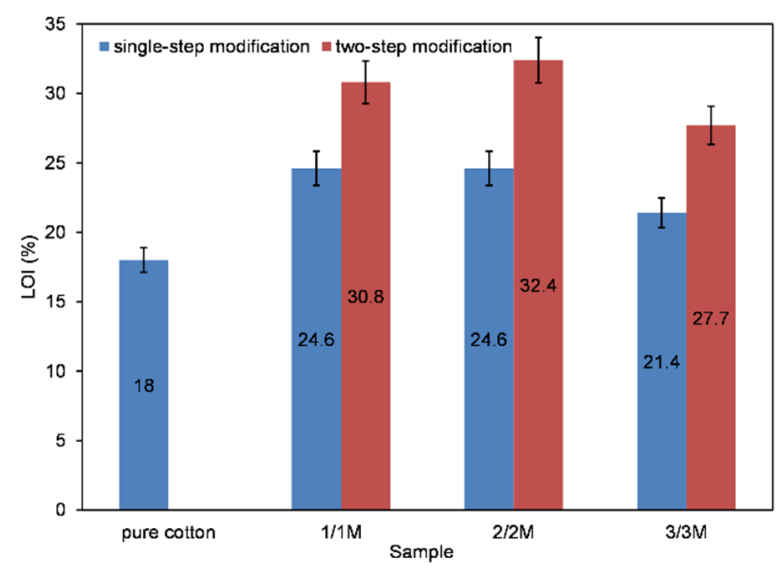

Figure 7. Limited oxygen indices of fabric samples.

The results presented in Figure 7 show that all applied modifications resulted in an increase in the oxygen index. LOI results are correlated with those obtained on PCFC and the best fire protective effect was achieved by modification with prepolymers 1 and 2 . All samples obtained in the two-stage process (mercerized) have an oxygen index high enough to be considered as difficult to ignite. The value of the limited oxygen index for $1 \mathrm{M}$ and $2 \mathrm{M}$ samples was as high as $30.8 \%$.

To additionally confirm the modifications, the SEM-EDS analysis was performed. Concentrations of $\mathrm{C}, \mathrm{O}, \mathrm{F}, \mathrm{Si}, \mathrm{F}$, and $\mathrm{P}$ atoms (expressed in wt.\%) in all modified samples is presented in Table 4.

Table 4. Concentrations of $\mathrm{C}, \mathrm{O}, \mathrm{F}, \mathrm{Si}$, and $\mathrm{P}$ atoms in cotton samples as determined by $\mathrm{X}$-ray microanalysis.

\begin{tabular}{|c|c|c|c|c|c|c|c|c|c|c|}
\hline \multirow{2}{*}{$\begin{array}{l}\text { Sample } \\
\text { Code }\end{array}$} & \multicolumn{5}{|c|}{ Before Washing } & \multicolumn{5}{|c|}{ After Washing } \\
\hline & $\mathrm{C}$ & $\mathbf{O}$ & $\mathrm{Si}$ & $\mathbf{F}$ & $\mathbf{P}$ & $\mathrm{C}$ & O & Si & $\mathbf{F}$ & $\mathbf{P}$ \\
\hline 1 & 31.2 & 58.5 & 0.8 & 7.7 & 0.8 & 31.7 & 59.7 & 0.6 & 6.5 & 0.5 \\
\hline $1 \mathrm{M}$ & 29.7 & 54.4 & 0.9 & 10.8 & 1.0 & 30.2 & 56.3 & 0.7 & 9.3 & 0.8 \\
\hline 2 & 32.5 & 63.5 & 1.1 & 1.4 & 0.8 & 32.8 & 64.1 & 0.7 & 0.4 & 0.6 \\
\hline $2 \mathrm{M}$ & 31.2 & 61.6 & 1.3 & 1.9 & 0.9 & 32.1 & 65 & 0.9 & 0.7 & 0.5 \\
\hline 3 & 32.2 & 63.3 & 1.9 & - & 1.6 & 31.9 & 65.3 & 1.3 & - & 0.3 \\
\hline $3 \mathrm{M}$ & 31.7 & 63.0 & 2.3 & - & 2.0 & 31.3 & 66.6 & 1.4 & - & 0.5 \\
\hline
\end{tabular}

The data presented in Table 4 confirm the presence of the modifier in all samples. The presence of silicon and phosphorus in all samples indicates that the fabrics have been successfully modified with the obtained preparations. Analysis of fabrics modified with prepolymers containing fluorinated phosphoric ester groups also showed the presence of fluorine. In the case of sample 1, the fluorine content is higher than in sample 2, which is a consequence of the higher content of this element in precursor 1. Samples 3 and $3 \mathrm{M}$ contain twice as much phosphorus as other fabrics, which is caused by the presence of two phosphorus atoms in the structure of the precursor used. In addition, there is a tendency that mercerized samples contain more elements indicating the presence of a used compounds. This indicates that mercerization has caused the attachment of a larger amount of modifier to the surface of the fabric. Analysis of the samples after washing shows that the modifiers remained on the surface of the fibers. However, the content of elements decreased, which indicates a partial leaching of compounds. The greatest reduction of element content can be observed for samples 3 and $3 \mathrm{M}$. This may be due to the lack of fluorinated substituents in compound 3. As already mentioned, the presence of hydrophobic fluorinated groups protects the compounds against water access and leaching.

In order to study the morphology of modified fabrics, SEM analysis of their surfaces was performed (Figure 8). 


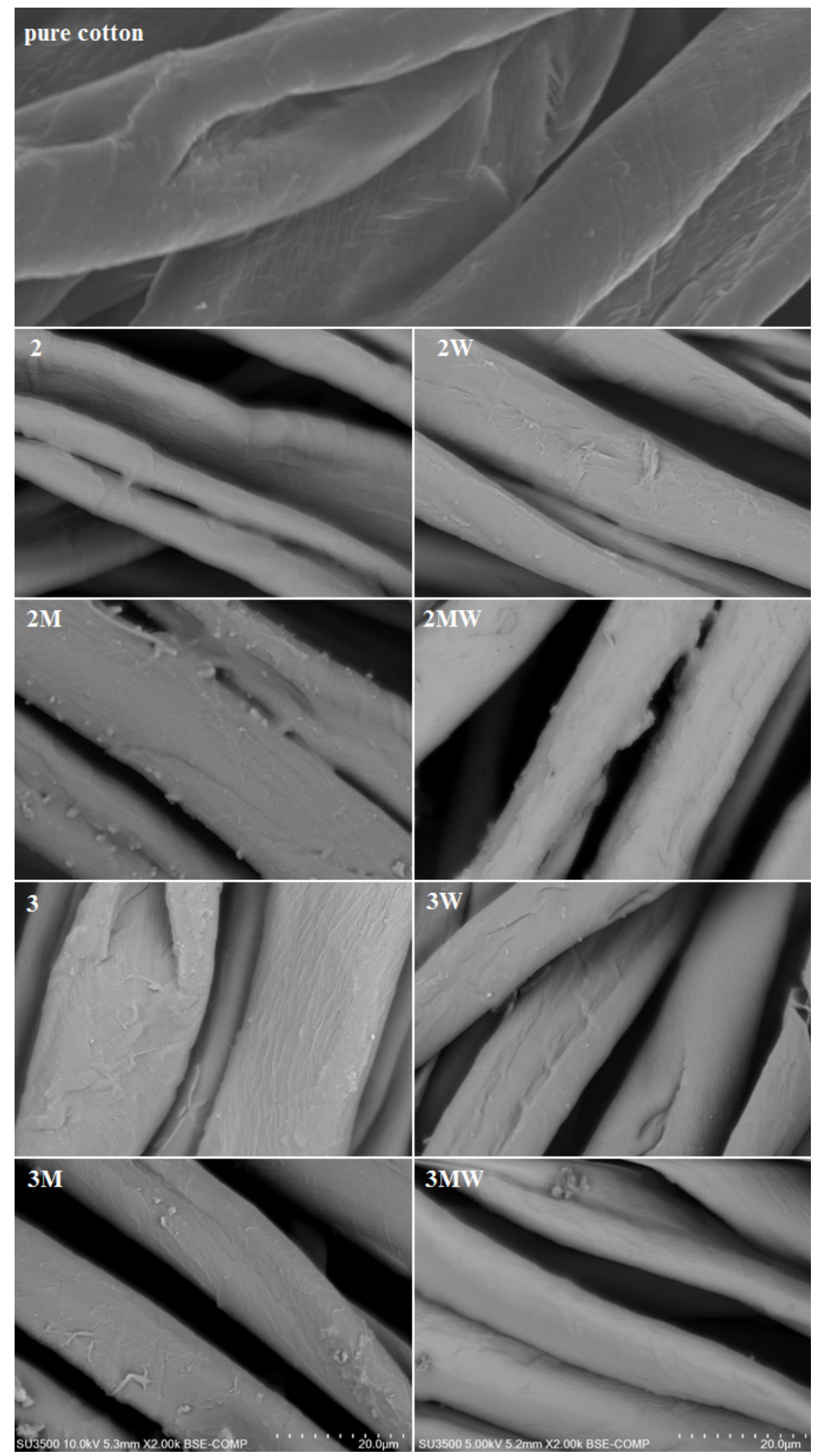

Figure 8. SEM image of pure cotton, samples modified by prepolymer 2 and 3, non mercerized, and mercerized $(\mathrm{M})$, before and after washing $(\mathrm{W})$.

By analyzing the SEM images shown in Figure 8, presence of the modifier layer can be observed on the surface of all impregnated samples regardless of the type of modifier used $(1,2$, or 3$)$ and the type of impregnation process applied. The micrographs show a layer 
of evenly distributed polymer surrounding each fiber. In the case of $2 \mathrm{M}$ and $3 \mathrm{M}$ samples impregnated in a two-step process, a few agglomerates are visible on their micrographs. The mercerization applied in the case of two-step impregnation procedure resulted in the deposition of a thicker layer of deposited polymers (samples 2M and 3M) compared to their non-mercerized analogous (samples 2 and 3). Washed fabrics modified with prepolymer 2 retained a modifier layer on the fibers surface (samples $2 \mathrm{~W}$ and 2MW). SEM images confirmed earlier observations that the presence of fluorinated groups protect the deposited coatings from leaching.

To further confirm the effect of fluoroalkyl or fluorophenyl groups on the surface properties of modified cotton samples, the hydrophobicity of the studied organosilicon flame retardant compounds was determined by measuring the water contact angle of unwashed samples and those subjected to the five-time washing process. The values of water contact angles of the silane-modified samples are presented in Figure 9.

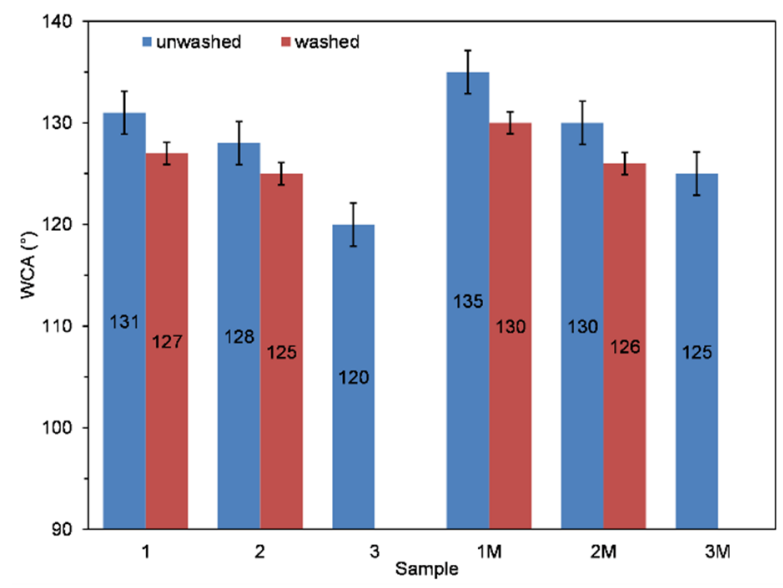

Figure 9. Water contact angles on the samples modified in signal and two-step process, measured before and after five washing cycles.

The modification of natural fabrics by organosilicon flame retardant prepolymers $(1,2$, and 3$)$ resulted in hydrophobization of the fabrics as reflected by values of water contact angles, which in all cases were above $120^{\circ}$. After washing, the hydrophobicity remained relatively stable in the case of samples modified by fluorinated phosphoric ester groups containing prepolymers. Fabrics modified with a composition 1 containing fluoroalkyl chains are characterized by the highest hydrophobicity (WCA of $135^{\circ}$ ), which is caused by the highest content of fluorine and its favorable distribution on the chain. The sample modified with a composition 2 containing fluorophenyl substituents is slightly less hydrophobic. Fabrics protected with a prepolymer 3 also exhibit hydrophobic properties, which is a consequence of the hydrocarbon and siloxane chains present in their structure. However, the hydrophobic effect disappears as a result of washing, which confirms the largest leaching of the coating devoided of fluorinated functional groups. Fluorinated groups are responsible for the hydrophobic effect of the modified fabric. These substituents of a hydrophobic nature can protect the surface of modified textile against water and partially prevent leaching as a result of C-O-Si bonds between the modifier and cellulose hydrolysis. The lack of fluorinated groups resulted in washing the modifier from the surface of the fabrics in the washing process. Therefore, the water-repellent effect after washing disappeared. In Figure 9 it can be seen that the fabric mercerization process resulted in an increase in the water contact angle values and hydrophobicity of modified samples. This is a consequence of the activation of the fiber surface and an increase in the number of active hydroxyl groups ready to bind with alkoxysilyl groups of flame retardant prepolymers. As a result, these compounds obtained better spatial organization of fluorinated groups, which translated into higher hydrophobicity of the samples modified with their use. 


\section{Conclusions}

The proposed synthetic procedure, based on the nucleophilic substitution and subsequent hydrosilylation processes, enabled the obtaining of prepolymers containing phosphoric acid silyl ester groups and their fluorinated analogs in their structure as precursors of multifunctional protective coatings of natural fabrics. The results of thermal, flammability, and surface tests of cotton fabric samples subjected to a single or two-stage impregnation with the obtained prepolymers confirmed their effectiveness as precursors of hydrophobic and flame-retardant coatings. It was also shown that the cotton fabric mercerization process (used in the case of two-stage impregnation) is of key importance for its effectiveness and significantly contributed to the intensification of the observed effects (increased hydrophobicity and reduced flammability of the tested samples). Particularly good results as the reduction in the total amount of heat released during the burning process by over $50 \%$, the reduction in the maximum heat release rate by about $75 \%$, shortening the time to ignition by almost 90 min compared to raw cotton, as well as increase in the limiting oxygen index to over 30 and the increase in the water contact angle to about $130^{\circ}$ were obtained for the samples modified with prepolymers 1 and 2 containing fluoroalkyl or fluorophenyl groups in their structure. Moreover, the results of discussed tests of samples subjected to the multiple washing processes showed that despite the partial degradation of the coatings produced as a result of hydrolysis of the $\mathrm{Si}-\mathrm{O}-\mathrm{C}$ bonds between the obtained prepolymers and cellulose, formed during the modification of cotton, they retained their hydrophobic properties and reduced flammability. At the same time, the test results showed that cotton samples modified with prepolymer 3, deprived of fluorinated functional groups, were characterized by significantly higher flammability, lower water contact angle, and hydrolytic stability, as evidenced by further deterioration of the discussed parameters measured for samples subjected to five washing cycles.

The obtained test results seem to confirm the synergy effect between the halides and phosphorus present in the structure of the precursors used for the production of protective coatings. Observed phosphorus-halide synergy can involve the action of halides in the gas phase as a free radical scavenger or the condensed phase as a blowing agent increasing the insulating char volume. As was mentioned, regardless of the mechanism of phosphorus-halides synergy, the understanding of which was not the aim of this work, and certainly requires more complex research, the presence of fluorine atoms in the structure of derivatives 1 and 2 unambiguously influenced observed flame-retardant effects.

Supplementary Materials: The following are available online at https:/ / www.mdpi.com/1996-194 4/14/6/1542/s1, Figure S1: Superimposed TG (a) and DTG (b) curves of cotton fabric samples modified with prepolymer 1 in single and two-step process before and after five washing cycles, Figure S2: Superimposed TG (a) and DTG (b) curves of cotton fabric samples modified with prepolymer 2 in single and two-step process before and after five washing cycles, Figure S3: Superimposed TG (a) and DTG (b) curves of cotton fabric samples modified with prepolymer 3 in single and two-step process before and after five washing cycles.

Author Contributions: Performed cotton fabrics modifications and wrote the manuscript-M.P.; conceptualized and planned the experiments, participated in writing the manuscript, and critically reviewed and revised the entire manuscript-M.D.; synthesized and characterized the obtained compounds, participated in writing the manuscript-K.S.; participated in the conceptualization, provided guidance during the planning of experiments and reviewed the manuscript-H.M.; performed and interpreted MCC and LOI measurements-S.R. All authors have read and agreed to the published version of the manuscript.

Funding: This work was supported by funds from the National Science Centre (Poland) granted on the basis of decision number DEC-2020/37/B/ST5/03266.

Institutional Review Board Statement: Not applicable.

Informed Consent Statement: Not applicable. 
Data Availability Statement: Data available on request due to privacy restrictions. The data presented in this study are available on request from the corresponding author. The data are not publicly available due to the lack of availability of a suitable repository.

Conflicts of Interest: The authors declare no conflict of interest. The funders had no role in the design of the study; in the collection, analyses, or interpretation of data; in the writing of the manuscript, or in the decision to publish the results.

\section{References}

1. Deepa, B.; Laly, A.P.; Rubie, M.S.; Sabu, T. Structure, properties and recyclability of natural fibre reinforced polymer composites. In Recent Developments in Polymer Recycling; Fainleib, A., Grigoryeva, O., Eds.; Transworld Research Network: Trivandrum, India, 2011; p. 101.

2. Jelil, R.A. A review of low-temperature plasma treatment of textile materials. J. Mater. Sci. 2015, 50, 5913-5943. [CrossRef]

3. Magovac, E.; Jordanov, I.; Grunlan, J.C.; Bischof, S. Environmentally-Benign Phytic Acid-Based Multilayer Coating for Flame Retardant Cotton. Materials 2020, 13, 5492. [CrossRef] [PubMed]

4. Tortizsch, J. Plastic Flammability Handbook. Principles_Regulations_-Testing and Approval; Carl Hanser Verlag: Munich, Germany, 2004.

5. Morgan, A.B.; Wilkie, C.A. Flame Retardant Polymer Nanocomposites; Wiley: Hoboken, NJ, USA, 2007.

6. Horrocks, A.R.; Kandola, B.K.; Davies, P.J.; Zhang, S.; Padbury, S.A. Developments in flame retardant textiles-A Review. Polym. Degrad. Stabil. 2005, 88, 3-12. [CrossRef]

7. Georlette, P. Applications of halogen flame retardants. In Fire Retardant Materials; Horrocks, A., Price, D., Eds.; Woodhead Publishing Ltd.: Boca Raton, FL, USA, 2001.

8. Camlibel, O. Flame-Retardant Unsaturated Polyester Resins: An Overview of Past and Recent Developments. In Polyester: Production, Characterization and Innovative Applications; IntechOpen: London, UK, 2017.

9. Choi, K.; Seo, S.; Kwon, H.; Kim, D.; Park, Y.T. Fire protection behavior of layer-by-layer assembled starch-clay multilayers on cotton fabric. J. Mater. Sci. 2018, 53, 11433-11443. [CrossRef]

10. Xu, B.; Ding, Y.; Qu, S.; Cai, Z. Superamphiphobic cotton fabrics with enhanced stability. Appl. Surf. Sci. 2015, 356, 951-957. [CrossRef]

11. Gao, Y.; He, C.; Huang, Y.; Qing, F.L. Novel water and oil repellent POSS-based organic/inorganic nanomaterial: Preparation, characterization and application to cotton fabrics. Polymer 2010, 51, 5997-6004. [CrossRef]

12. Horrocks, A.R.; Wang, M.Y.; Hall, M.E.; Sunmonu, F.; Pearson, J.S. Flame retardant textile back-coatings. Part 2. Effectiveness of phosphorus-containing flame retardants in textile back-coating formulations. Polym. Int. 2000, 49, 1079-1091. [CrossRef]

13. Liu, Z.; Xu, M.; Wang, Q.; Li, B. A novel durable flame retardant cotton fabric produced by surface chemical grafting of phosphorus-and nitrogen-containing compounds. Cellulose 2017, 24, 4069-4081. [CrossRef]

14. Qiang-Lin, L.I.; Huang, F.Q.; Wei, Y.-J.; Wu, J.-Z.; Zhou, Z.; Liu, G. A Phosphorus-Nitrogen Flame-retardant: Synthesis and Application in Cotton Fabrics. Mater. Sci. 2018, 24, 448-452.

15. Gaan, S.; Sun, G. Effect of phosphorus flame retardants on thermo-oxidative decomposition of cotton. Polym. Degrad. Stab. 2007, 92, 968-974. [CrossRef]

16. Gaan, S.; Sun, G.; Hutches, K.; Engelhard, M.H. Effect of nitrogen additives on flame retardant action of tributylphosphate: Phosphorus-nitrogen synergism. Polym. Degrad. Stab. 2008, 93, 99-108. [CrossRef]

17. Li, Q.; Jiang, P.; Su, Z.; Wei, P.; Wang, G.; Tang, X. Synergistic effect of phosphorus, nitrogen, and silicon on flame-retardant properties and char yield in polypropylene. J. Appl. Polym. Sci. 2005, 96, 854. [CrossRef]

18. Suryaprabha, T.; Sethuraman, M.G. Fabrication of a superhydrophobic and flame-retardant cotton fabric using a DNA-based coating. J. Mater. Sci. 2020, 1-11. [CrossRef]

19. Nguyen, H.K.; Sakai, W.; Nguyen, C. Preparation of a Novel flame retardant formulation for cotton fabric. Materials 2020, $13,54$. [CrossRef]

20. Alongi, J.; Ciobanu, M. Malucelli G. Sol-gel treatments of cotton fabrics for improving thermal and flame stability: Effect of the structure of the alkoxysilane precursor. Carbohydr. Polym. 2012, 87, 627-635. [CrossRef]

21. Alongi, J. Novel flame retardant finishing system for cotton fabric based on phosphorus-containing compounds and silica derived from sol-gel process. Carbohydr. Polym. 2011, 85, 599-608. [CrossRef]

22. Periyasamy, A.P.; Venkataraman, M.; Kremenakova, D.; Militky, J.; Zhou, Y. Progress in Sol-Gel Technology for the Coatings of Fabrics. Materials 2020, 13, 1838. [CrossRef] [PubMed]

23. Periolatto, M.; Ferrero, F.; Montarsolo, A.; Mossotti, R. Hydrorepellent finishing of cotton fabrics by chemically modified TEOS based nanosol. Cellulose 2013, 20, 355-364. [CrossRef]

24. Malucelli, G.; Carosio, F.; Alongi, J.; Fina, A.; Frache, A.; Camino, G. Materials engineering for surface-confined flame retardancy. Mater. Sci. Eng. R Rep. 2014, 84, 1-20. [CrossRef]

25. Horrocks, A.R. An introduction to the burning behavior of cellulosic fibres. J. Soc. Dyers Colour 1983, 99, 191-197. [CrossRef]

26. Wu, W.; Yang, C.Q. Comparison of different reactive organophosphorus flame retardant agents for cotton: Part I. The bonding of the flame retardant agents to cotton. Polym. Degrad. Stab. 2006, 91, 2541-2548. [CrossRef]

27. Liu, C.; Xing, T.; Wei, B.; Chen, G. Synergistic effects and mechanism of modified silica sol flame retardant systems on silk fabric. Materials 2018, 11, 1842. [CrossRef] [PubMed] 
28. Szolnoki, B.; Bocz, K.; Sóti, P.L.; Bodzay, B.; Zimonyi, E.; Toldy, A.; Morlin, B.; Bujnowicz, K.; Wladyka-Przybylak, M.; Marosi, G. Development of natural fibre reinforced flame retarded epoxy resin composites. Polym. Degrad. Stab. 2015, 119, 68-76. [CrossRef]

29. Hu, S.; Hu, Y.; Song, L.; Lu, H. Effect of modified organic-inorganic hybrid materials on thermal properties of cotton fabrics. J. Therm. Anal. Calorim. 2011, 103, 423-427. [CrossRef]

30. Zhao, P.; Liu, S.; Xiong, K.; Wang, W.; Liu, Y. Highly flame retardancy of cotton fabrics with a novel phosphorus/nitrogen/silicon flame-retardant treating system. Fiber Polym. 2016, 17, 569-575. [CrossRef]

31. Tian, P.; Lu, Y.; Wang, D.; Zhang, G.; Zhang, F. Solvent-free synthesis of silicon-nitrogen-phosphorus flame retardant for cotton fabrics. Cellulose 2019, 26, 6995-7007. [CrossRef]

32. Zhao, X. Synthesis and application of a durable phosphorus/silicon flame-retardant for cotton. J. Text. Inst. 2010, 101, 538-546. [CrossRef]

33. Chen, Z.; Dong, C.; Li, Q.; Bai, Y.; Lu, Z. Preparation of linear piperazine/phosphorous/polysiloxane copolymer and its application on cotton fabrics. J. Therm. Anal. Calorim. 2017, 130, 1997-2005. [CrossRef]

34. Dong, C.; Lu, Z.; Zhang, F.; Zhu, P.; Wang, P.; Che, Y.; Sui, S. Combustion behaviors of cotton fabrics treated by a novel nitrogen-and phosphorus-containing polysiloxane flame retardant. J. Therm. Anal. Calorim. 2016, 123, 535-544. [CrossRef]

35. Przybylak, M.; Maciejewski, H.; Dutkiewicz, A.; Wesołek, D.; Władyka-Przybylak, M. Multifunctional, strongly hydrophobic and flame-retarded cotton fabrics modified with flame retardant agents and silicone compounds. Polym. Degrad. Stab. 2016, 128, 55-64. [CrossRef]

36. Dutkiewicz, M.; Przybylak, M.; Januszewski, R.; Maciejewski, H. Synthesis and flame retardant efficacy of hexakis (3(triethoxysilyl)propyloxy)cyclotriphosphazene/silica coatings for cotton fabrics. Polym. Degrad. Stab. 2018, 148, 10-18. [CrossRef]

37. Przybylak, M.; Maciejewski, H.; Dutkiewicz, A. Preparation of highly hydrophobic cotton fabric by modification with bifunctional silsesquioxanes in the sol-gel process. Appl. Surf. Sci. 2016, 387, 163-174. [CrossRef]

38. Przybylak, M.; Maciejewski, H.; Dutkiewicz, A.; Dabek, I.; Nowicki, M. Fabrication of superhydrophobic cotton fabrics by a simple chemical modification. Cellulose 2016, 23, 2185-2197. [CrossRef]

39. Textiles-Tests for color fastness - Color fastness to domestic and commercial laundering; PN-EN ISO 105-C06:2010; Polish Committee for Standardization: Warsaw, Poland, 2013.

40. Determination of flammability by the oxygen index method; PN-EN ISO 4589-2:2017-06; Polish Committee for Standardization: Warsaw, Poland, 2017.

41. Alongi, J.; Ciobanu, M.; Malucelli, G. Sol-gel treatments for enhancing flame retardancy and thermal stability of cotton fabrics: Optimisation of the process and evaluation of the durability. Cellulose 2011, 18, 167-177. [CrossRef]

42. Alongi, J.; Malucelli, G. State of the art and perspectives on sol-gel derived hybrid architectures for flame retardancy of textiles. J. Mater. Chem. 2012, 22, 21805-21809. [CrossRef]

43. Yang, Z.; Wang, X.; Lei, D.; Fei, B.; Xin, J.H. A durable flame retardant for cellulosic fabrics. Polym. Degrad. Stab. 2012, 97, 2467-2472. [CrossRef]

44. Wang, S.; Sui, X.; Li, Y.; Li, J.; Xu, H.; Zhong, Y.; Zhang, L.; Mao, Z. Durable flame retardant finishing of cotton fabrics with organosilicon functionalized cyclotriphosphazene. Polym. Degrad. Stab. 2016, 128, 22-28. [CrossRef]

45. Alongi, J.; Malucelli, G. Cotton flame retardancy: State of the art and future perspectives. RSC Adv. 2015, 5, 24239-24263. [CrossRef]

46. Pereira, C.M.C.; Martins, M.S.S. Flame retardancy of fiber-reinforced polymer composites based on nanoclays and carbon nanotubes. In Polymer Green Flame Retardants; Elsevier: Amsterdam, The Netherlands, 2014; pp. 551-595.

47. Tian, L.; Li, X.; Wang, L.; Zhang, Y.; Cui, J.; Guo, J.; Yang, B. Synthesis and characterization of an efficient flame retardant based on aromatic ring and phosphate ester for epoxy resin. Polym. Eng. Sci. 2019, 59, E406-E413. [CrossRef]

48. Davies, P.J.; Horrocks, A.R.; Alderson, A. Possible phosphorus/halogen synergism in flame retardant textile backcoatings. Fire Mater. 2002, 26, 235-242. [CrossRef]

49. Mostashari, S.M.; Fayyaz, F. A combination of red phosphorus-zinc chloride for flame-retardancy of a cotton fabric. Int. J. Polym. Mater. 2007, 57, 125-131. [CrossRef]

50. Lewin, M. Synergistic and catalytic effects in flame retardancy of polymeric materials-An overview. J. Fire Sci. 1999, 17, 3-19. [CrossRef] 